\title{
Prosthodontics in 2019 and beyond
}

Peter Briggs, Bart's and The London School of Medicine and Dentistry, Queen Mary University of London, Dental Institute, London

E1 2AD; Shiyana Eliyas, St George's University Hospitals NHS Foundation Trust, Blackshaw Road, Tooting, London, SW17 0QT

The $B D J$ Upfront section includes editorials, letters, news, book reviews and interviews. Please direct your correspondence to the News Editor,

Kate Quinlan at k.quinlan@nature.com. Press releases or articles may be edited, and should include a colour photograph if possible.

$\mathrm{P}$ rosthodontics and advanced operative dentistry may have been thought of as dying arts a decade ago, following evidence of substantial reductions in oral disease within the UK population. ${ }^{1,2}$ The hope being that improved oral health/reduced disease, will help move dentistry away from complex mechanical interventions to a more biological, preventive, supportive and holistic approach to delivery of care. The rapid ageing
The future workforce will need to understand medicalisation of the dental patient, for example more and more patients will present with a history of anti-angiogenic medications such as bisphosphonates. These patients will live for longer and dental extractions may be contraindicated for life. ${ }^{6}$ With increase in head and neck cancer and better overall survival figures ${ }^{7}$ and a desire for a high quality of life, many patients are heading into survivorship wanting dental

\section{'Prosthodontics is a combination of science and "the art" of a craft skill'}

shift of the UK population has created a different and difficult challenge for the dental profession, ${ }^{3}$ with patients requiring more complicated interventions to preserve their natural teeth. These patients may be more likely to request treatment to retain their own teeth and choose 'fixed' prosthodontic solutions in response to tooth loss.

On one hand, younger patients have a low treatment need, with more prevention, early intervention and, where possible, newer additive adhesive techniques for pathologies such as toothwear. On the other, we have older patients with more complex medical and oral needs living with long-term illnesses, possibly demanding difficult conventional prosthodontic interventions.

Much has been learned about the long-term biological maintenance responsibilities associated with fixed, removable and implant rehabilitations. ${ }^{4}$ Compared to 15 years ago the pendulum seems to have swung towards supporting retention of natural teeth for as long as possible before considering prosthodontic replacements. ${ }^{5}$ prosthodontic rehabilitation and maintenance for functional and aesthetic reasons.

Prosthodontics is a combination of science and 'the art' of a craft skill. A wide variety of skills are required to provide safe and effective prosthodontic intervention and these need to evolve with the changing needs of the population. The upskilling of carers as well as access to dental care professionals (DCPs) for both the younger patients and the aging population, who may not be able to maintain good oral health without help, will be essential. ${ }^{8}$

We are delighted to be guest editors of this prosthodontics themed issue of the $B D J$, giving us the opportunity to invite experts from around the world to contribute to this edition. We hope you agree that this is an informative and thought provoking issue, covering several areas of contemporary clinical practice with focus on the future, to include: the importance of prevention; impact of bleaching on prosthodontics; successful use of temporary restorations; advances in materials and concepts to allow selection of different prosthodontic treatment modalities; an update on the value of root-filled teeth to maintain a functional dentition; development of coronal tooth tissue with a minimally invasive surgical extrusion technique; and the consequences of using linings beneath composite restorations. We also thought it appropriate that the edition should highlight current concepts and novel techniques in the prosthodontic management of head and neck cancer patients, with few more worthy of highly skilled care. Finally, there are also two papers that focus on education and training with relevance to 'craft skills' and early career development. We thank all authors who submitted papers for inclusion within this edition and hope that readers enjoy this $B D J$ issue on prosthodontics.

\section{References}

1. Fuller E, Steele J, Watt R, Nuttall N. Oral health and function - a report from the Adult Dental Health Survey 2009.2011. Available at https://files.digital.nhs.uk/publicationimport/pub01xxx/pub01086/adul-dent-heal-survsumm-them-the1-2009-rep3.pdf (accessed April 2019).

2. White D, Pitts N, Steele J, Sadler K, Chadwick B. Disease and related disorders - a report from the Adult Dental Health Survey 2009. 2011. Available at https://files. digital.nhs.uk/publicationimport/pub01xxx/pub01086/ adul-dent-heal-surv-summ-them-the2-2009-rep4.pdf (accessed April 2019).

3. Steele J, Treasure E, Fuller L, Morgan M. Complexity and maintenance - a report from the Adult Dental Health Survey 2009. 2011. Available at https://files.digital.nhs. uk/publicationimport/pub01xxx/pub01086/adul-dentheal-surv-summ-them-the4-2009-rep6.pdf (accessed April 2019)

4. Pjetursson B E, Asgeirsson A G, Zwahlen M, Sailer I. Improvements in implant dentistry over the last decade: comparison of survival and complication rates in older and newer publications. Int J Oral Maxillofac Implants 2014; 29 Suppl: 308-324.

5. Salloum $S$, Houseini $H$, Bassam $S$ et al. Endodontic retreatment v/s implant. J Dent Health Oral Disord Ther 2018; 9: 245-248.

6. Ballantyne E. Bisphosphonates: possible modes of action and implications for dental implant treatment. A review of the literature. J Gen Pract 2014; 3: 1.

7. Cancer Research UK. One-, five- and ten-year survival for head and neck cancers. https://www.cancerresearchuk.org/health-professional/cancer-statistics/ statistics-by-cancer-type/head-and-neck-cancers/ survival\#heading-Zero (accessed April 2019).

8. Mouth Care Matters. Parliamentary debate and Mouth Care Matters. 2019. Available at http://www.mouthcarematters. hee.nhs.uk/?p=2209 (accessed April 2019).

DOI: $10.1038 / s 41415-019-0370-z$ 